\title{
Numerical modelling of the thermal energy demand in Italian households through statistical data
}

\author{
Matteo Caldera ${ }^{1 *}$, Giovanni Puglisi ${ }^{1}$, Fabio Zanghirella ${ }^{1}$, Paola Ungaro $^{2}$, Giuliano Cammarata ${ }^{3}$ \\ ${ }^{1}$ ENEA (Italian National Agency for New Technologies, Energy and Sustainable Economic Development), via Anguillarese \\ 301, 00123 Roma, Italy \\ ${ }^{2}$ ISTAT (Italian National Institute of Statistics), viale Oceano Pacifico 171, 00144 Roma, Italy \\ ${ }^{3}$ Università degli Studi di Catania, piazza Università 2, 95125 Catania, Italy
}

Corresponding Author Email: matteo.caldera@enea.it

https://doi.org/10.18280/ijht.360201

Received: 13 October 2017

Accepted: 10 April 2018

\section{Keywords:}

energy consumption, households, numerical model, statistical survey

\begin{abstract}
The availability of reliable and up-to-date data on energy uses and consumption is a key aspect in order to achieve the goals set out by European Directives on energy efficiency, and to monitor the effectiveness of energy policies supporting buildings' retrofit actions. In such a context, a numerical model, implemented in Excel ${ }^{\circledR}$ and Matlab ${ }^{\circledR}$, was developed in order to determine the energy consumption for space heating, domestic hot water and cooking in households, based on a statistical dataset of 20,000 records collected in a survey on the energy consumption of Italian families carried out by the National Institute of Statistics (ISTAT). The space heating model is based on the definition of classes of dwelling-types, while the energy use for DHW and cooking are calculated on a record-by-record basis according to a Standardbased approach. The present paper presents the results of a refined version of the model, in particular the calibration of relevant parameters accounted for the secondary equipment for space heating, resulting in improvements in the reliability for the allocation of the fuel consumption among the end-uses. The refinement and validation of the model are still in progress, since they are functional for the assessment of the energy consumption of households in the period between two subsequent surveys.
\end{abstract}

\section{INTRODUCTION}

European policies encourage solutions for the reduction of the energy demand and the improvement of energy efficiency in the residential sector, which covers by itself around $30 \%$ of the total primary energy demand. In Italy, current Laws [1-2] provide financial incentives for energy retrofit measures addressed both to the envelope and to the energy system. They are mainly in the form of tax deduction covering part of the investment costs (from $65 \%$ up to $75 \%$ for common parts of block of flats) and accorded in ten years, or of capital grant covering variable quotas of the investment costs and given in two to five years. Just a few numbers, taken from ENEA's Annual report on energy efficiency [3], which demonstrate the performance of these incentives: the mechanism "Ecobonus" (i.e. tax deductions) financed around one million of retrofit interventions during the period 2014-2016, and in the last year, it activated 3.3 Billion Euro of investments mainly for the replacement of windows (50\%) and of heating systems (20\%), and for the installation of solar shadings (12\%). Moreover, the incentive "Conto Termico" (i.e. capital grant), which addresses to the improvement of the energy efficiency and the use of renewables for thermal energy production, registered in 2016 an increase $+80 \%$ of requests with respect of 2015 .

In such a context, the availability of reliable and up-to-date data on energy uses and consumption is a key aspect in order to achieve the goals set out by Directives and to monitor the effectiveness of energy policies supporting buildings' retrofit actions. In response to these needs, the Regulation EC/1099/2008 of the European Parliament and of the Council of 22 October 2008 on energy statistics, and the amending Commission Regulation EU/431/2014 of 24 April 2014 on energy statistics require Member States to provide data on the annual energy consumption of households for final destination and energy source.

In Italy, the National Institute of statistics (ISTAT), in collaboration with the National Agency for energy and sustainable economic development (ENEA) and the Ministry for the economic development (MiSE), carried out a survey on households' energy consumption to comply the obligation. The survey was conducted in 2013 on a representative sample of 20,000 households and provided information on the consumption habits, the characteristics and types of plant, and on the energy expenditures of Italian households specified by energy carrier. These data provide a comprehensive overview of the residential sector in the National energy context and represent an official background for the development of future energy strategies addressed to domestic users.

The assessments of the energy savings potential and of the impact of public energy policies aimed at retrofitting existing buildings are complex tasks. Energy consumption and potential energy savings depend not only on the objective characteristics of the building and of the thermal equipment, but also on the occupants' behaviour [4-5], and on urban and socio-economic variables [6].

Many models and software are currently available for the evaluation of the energy performance and the cost-optimal analysis of existing dwellings, also intended for energy audits, but they generally perform detailed simulations of single buildings on an hourly basis [7] and therefore they are time- 
consuming and not suitable for large-scale scenarios. Approaches based on statistical data are more effective in evaluating the energy consumption on an urban, regional or national scale. They can consider building typologies, the socalled building types that is a reference building for an entire building category [8]. Alternatively, representative building samples employ a group of buildings instead of a single reference dwelling, in order to represent the whole category by accounting for the heterogeneous characteristics of the various cases. On the other hand, statistical analyses of a robust reference dataset or hybrid deterministic-statistical models can be considered to find simplified correlations for the assessment of the energy demand [9].

The availability of accurate data and their level of detail and aggregation play a fundamental role in the implementation and calibration of energy models, which can be used not only to evaluate the observed energy consumption on different spatial and temporal scales but also to make predictions, e.g. based on a historical dataset and on forecasting data [10-11].

The present paper describes the results of a refined model, implemented in Excel $^{\circledR}$ and Matlab ${ }^{\circledR}$, aimed at determining the energy consumption for space heating, domestic hot water (DHW) and cooking in the Italian residential sector, based on the dataset from ISTAT survey. The results were obtained from the updated version of a numerical tool, which was presented at the AIGE-IIETA Conference 2017. The space heating model relied on the definition of classes of dwellingtypes, by accounting for the geometrical and thermo-physical properties of the dwellings. The energy consumption for DHW and cooking were calculated on a record-by-record basis according to a Standard-based approach. In the current version of the tool, the calibration of relevant parameters specifically used for DHW and cooking accounted for secondary equipment for space heating, resulting in improvements for the allocation of the fuel consumption among the end-uses. The refinement and validation of the model are still in progress, since they are functional for the assessment of the energy consumption of households in the period between two subsequent surveys.

\section{METHODOLOGY}

The numerical tool consisted of two sets of models for the estimation of the energy demand in the residential sector: one set for the space heating and the other for DHW and cooking uses. The input data were obtained from the ISTAT survey.

The models, which were described in [12], were revised and updated. In particular, the secondary equipment for space heating has been accounted for the selection of the records required by the calibration of relevant parameters. For each end use, a three-dimensional matrix was created in order to allocate the fuel and the type of system (centralised, independent, local appliances for space heating and DHW, ovens and hobs for cooking) for the complete dataset on a record-by-record basis, regardless of the primary or auxiliary function.

Moreover, the revision of the model included the automated algorithm for the congruity check of the dataset, the algorithm for the calculation of the actual occupation of the apartment by the family members during the reference year, the algorithm for DHW production, and new reference prices for natural gas and LPG based on regional data instead of national averages. The most important features of the updated models are summarised below.

\subsection{Space heating}

Keeping in mind the objectives of the activity, the methodology selected for the space heating model was a compromise between the type and level of detail of the information provided by the survey, and the level of complexity required by the simulations. These constraints led to the definition of classes of dwelling-types; the national residential building stock was subdivided into twenty classes of dwellings, summarized in Table. The classification of the dwelling-types accounted for the:

- Year of construction: before 1950, 1950-1969, 19701989, after 1990;

- Type of dwelling: single-family house, multi-family house, ground floor apartment, middle floor apartment and top floor apartment.

The core of the space heating model relied on the equivalent resistance-capacitance model $\mathrm{R} 5 \mathrm{C} 1$ described in [13] and based on the European standard EN ISO 13790 [14], and it was implemented in Excel $^{\circledR}$.

Table 1. Dwelling type classes for the space heating model

\begin{tabular}{c|cccc}
\hline Type of & \multicolumn{4}{|c}{ Construction period } \\
Dwelling * & Before 1950 & 1950-'69 & 1970-'89 & After 1990 \\
\hline SFH & DTC1 & DTC6 & DTC11 & DTC16 \\
MFH & DTC2 & DTC7 & DTC12 & DTC17 \\
GFA & DTC3 & DTC8 & DTC13 & DTC18 \\
MFA & DTC4 & DTC9 & DTC14 & DTC19 \\
TFA & DTC5 & DTC10 & DTC15 & DTC20 \\
\hline * Note. SFH: single-family house; MFH: multi-family house; GFA: ground \\
floor apartment; MFA: middle floor apartment; TFA: top floor apartment.
\end{tabular}

The main information obtained by the survey were:

- Characteristics of the envelope of the building, for the definition of the classes of dwelling-types;

- Characteristics of the primary heating systems, for the estimation of the global seasonal efficiencies;

- Hours of operation of the heating systems, for the reduction factor for intermittent heating;

- Energy expenditure for the fuel, for the model validation. The model estimated the energy consumption for space heating through the following steps:

1. Calculation of the thermal energy demand under continuous operation of each dwelling-type in five climatic zones;

2. Calculation, for each dwelling-type class in each climatic zone, of the reduction factor for intermittent operation, based on the average number of hours per day when the heating system was turned on;

3. Assumption of reference values for the global efficiency of the different types of heating plant, for each dwelling-type class in each climatic zone;

4. Calculation of the primary energy demand under intermittent operation, for each dwelling-type class in each climatic zone;

5. Estimation of the total annual energy consumption for space heating for each dwelling-type class on a national basis.

In order to perform the calculations for each climatic zone, the weather data (temperature, radiation and humidity) referred to the main town whose heating degree-days (HDD) was "barycentric" with respect to the HDD in each climatic 
zone.

\subsection{Domestic hot water}

The model was implemented in Matlab ${ }^{\circledR}$, and analysed the energy consumption for DHW production for each single household of the survey by means of a Standard-based approach. Moreover, the relevant parameters were obtained from the analysis of the state of the art, BATs and a market survey of domestic equipment.

Two options were available for the calculation of the energy demand for DHW: either according to the number of occupants or to the floor area of the apartment. The average daily hot water demand was estimated according to the Italian Standard UNI 9182 [15] in the former case, and according to Standard UNI/TS 11300:2 [16] in the latter case. In the present context, the approach based on the number of occupants was followed, and the annual DHW net energy demand was calculated with the following relation:

$$
Q_{D H W}=K_{r} \cdot c_{w} \cdot V_{w, o c c} \cdot \Delta T_{w} \cdot \sum_{o c c} d_{o c c}
$$

where:

- $K_{\mathrm{r}}$ is a correction factor provided by [15], which accounted for the number of rooms in the apartment;

- $c_{\mathrm{w}}$ is the thermal capacity of water, i.e. $1.162 \cdot 10^{-3}$ $\mathrm{kWh} / \mathrm{kg} / \mathrm{K}$;

- $V_{\mathrm{w}, \text { occ }}$ is the average daily hot water demand per capita (in litres);

- $\Delta T_{\mathrm{w}}=25^{\circ} \mathrm{C}$ is the temperature difference of water, i.e. the supply temperature was set to $40^{\circ} \mathrm{C}$ while mains were set to $15^{\circ} \mathrm{C}$;

- $d_{\text {occ }}$ is the number of days in a year of occupation of the apartment by each component of the family.

If solar collectors for DHW production were available, the annual contribution of solar thermal was estimated by considering the number of solar collectors and the typical design solar fractions for DHW, and it was deducted from the net energy demand.

The model accounted only for the main/primary DHW heating system, as secondary DHW system were sporadic (present in just $3.3 \%$ of the records of the survey). The equipment efficiencies were determined according to the reference values reported in [16-17], as a function of the fuel, of the age and type of the system (local boiler, independent or centralised system).

As anticipated, new features were added in the current version of the model, in order to refine its accuracy. In particular, heat loss coefficients were associated to the presence of thermal energy storages and of recirculation piping. DHW recirculation was accounted in centralised systems installed after 1990 and in independent systems installed after 2000. The absence of water recirculation in the older systems was accounted by an extra hot water demand.

\subsection{Cooking}

Similarly, the model for cooking was implemented in Matlab $^{\circledR}$ and calculated the energy consumption for each single record by means of a Standard-based approach. Moreover, the relevant parameters were obtained from the analysis of the state of the art, BATs and a market survey of domestic appliances. In agreement with Eurostat guidelines
[18] only ovens and hobs were considered, since small appliances (e.g. microwave ovens, kettles, coffee makers and toasters) generally have a sporadic or limited use. Energy consumption was correlated to the number of occupants, corrected in order to account for periods spent away.

The theoretical basis of the model was obtained from the European Commission Regulations on Ecodesign requirements [19-20], and Standard EN 60350 [21] on methods for measuring the performance of household electric cooking appliances. ISTAT survey provided the type of fuel, the usage frequency of ovens and hobs, and the classes of age and size for the ovens.

The energy consumption of a single cycle $\left(E C_{\text {oven }}\right)$ for electrical and gas-fired ovens was calculated with the following formula [19]:

$E C_{\text {oven }}=S E C \cdot \frac{E E I}{100}$

where $E E I$ is the energy efficiency index of the ovens in a single cycle, while $S E C$ is the standard energy consumption required to heat up a normalized load during a cycle, which depended on the energy source and was calculated according to one of the following relations:

- Electrical ovens (in kWh):

$S E C=0.0042 \times V+0.55$

- Gas fired ovens (in MJ):

$S E C=0.0440 \times V+3.53$

where $V$ is the volume of the cavity, extrapolated from the classes provided by the ISTAT survey: small (assumed equal to $40 \mathrm{~L})$, medium $(54 \mathrm{~L})$, and large $(65 \mathrm{~L})$. As for the other fuels, no data were available from the survey, hence ovens fueled with gas or LPG were assumed with $V=65 \mathrm{~L}$ based on a market analysis. The SEC for LPG ovens was calculated with the formula (5) as well.

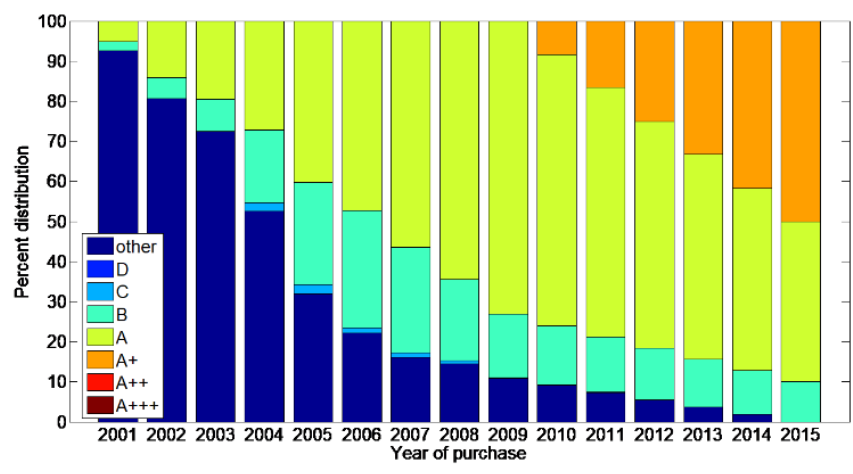

Source: ENEA elaborations of Gfk data from [22]

Figure 1. Energy efficiency index of ovens

The index EEI, which defined the energy efficiency class of the ovens according to the European classification [19], was estimated according to the age; as shown in Figure 1, an EEI value was calculated for each year, according to the weighted average of the energy efficiency classes of ovens sold in that year. Data related to the sales of ovens according to the energy labelling in the Italian market up to 2009 were taken from Gfk database, as reported in [22], while the extrapolation for the 
following years was based on a market survey [23].

Eq. (3) to (5) refer to a normalized cooking cycle, which was considered equivalent to the energy demand of two occupants. The annual energy consumption was then calculated by multiplying the energy demand times the average weekly usage frequency of the oven provided by the survey.

A slightly different model was used for the hobs, because no historical sales data were available. The energy consumption of a single cooking cycle $E C_{\text {hob }}$ was calculated as the ratio between the energy demand $E D_{\text {hob }}$, i.e. the theoretic minimum energy in a single cooking cycle, and the average hob efficiency $\varepsilon_{\text {hob }}$

$$
E C_{h o b}=\frac{E D_{h o b}}{\varepsilon_{h o b}}
$$

Normalised tests, which include heating up and keeping the temperature for a defined period, were considered representative of a typical household cooking process [21]. As described in the results, the average mass load per cooking cycle was determined in order to minimise the median deviation between the data from the survey and the results of the model. While $E D_{\text {hob }}$ was assumed independent of the fuel (it refers to a normalised load), the efficiency depended on the hob type. Missing the data on the specific technology (e.g. electrical resistance, radiant, induction), electrical hobs were assumed inductive; a market analysis showed that induction hobs represented the majority of electrical units and the most efficient category. Reference efficiency depended on the type of fuel, and these values were selected [24-25]:

- Electrical: 74\%;

- Natural gas: $40 \%$;

- LPG: $45 \%$;

- Biomass: $14 \%$.

According to Annex I of [20] and to a market analysis [23], the normalised energy consumption $\left(E C_{\text {hob }}\right)$ for induction hobs was assumed equal to $230 \mathrm{Wh} / \mathrm{kg}$. Therefore, according to Eq. (6), it was possible to calculate the energy demand ( $\left.E D_{\mathrm{hob}}\right)$ and, finally, the energy consumption for the other fuels. Hence, the annual energy consumption of the hobs was obtained by multiplying the energy demand per cycle times the number of occupants' times the average weekly usage frequency and the actual occupation period of each person.

\subsection{Calibration of the model}

As described in the previous sections, the results of the model for DHW and cooking depended on some parameters, which provided average information on the energy uses of Italian families. The calibration of such parameters was done by comparing the results of the model with the energy consumption calculated for each household from the expenditures of the last 12 months obtained from the ISTAT survey. In the selected records, the fuel was used only for a specific end-use (e.g. only for cooking), in order to avoid approximations associated with the extrapolation of the energy consumption of the other end-uses. Therefore, it was not possible to consider electricity, because electrical appliances, lighting and space cooling strongly affect the electrical bill. The ongoing activity on the model is addressing to this issue, and the next versions will include electrical appliances and space cooling in order to extend the validation related to all domestic end-uses.
The calibration consisted in a single-parameter tuning for each end-use. The selected parameters were the average load per cycle of the hobs for cooking (i.e. the mass of water heated up according to a Standard test procedure [21]), and the average daily hot water demand per capita for DHW production. These parameters depended mainly on the occupants' behavior; therefore, the values obtained with the selected fuel were applied also to the other fuels with an acceptable approximation.

The preliminary step consisted in converting into energy values the expenditures collected by the survey. As mentioned above, the survey provided the annual costs from the bill of the main fuels in the last 12 months between the second semester of 2012 and the second semester of 2013, without distinction of the type of end-use. Therefore, it was necessary to select proper average end prices of the fuels for that period and for the domestic market. The current version of the numerical code calculated the average prices per kilowatt-hour of natural gas and LPG on a regional scale, which was an improvement of the average national prices used in.

As regards natural gas, the final price with tax was determined with reference to the economic conditions of the protected market set by the Italian National Authority (AEEGSI) [26], by considering the variable network component, the regional surtax and the excise duty for each Region. The calculation of the energy consumption of gas in terms of kilowatt-hour accounted for the ranges of gas consumption defined by AEEGSI, and for a lower heating value $\mathrm{LHV}=9.59 \mathrm{kWh} / \mathrm{Sm}^{3}$ (since the system efficiencies referred to the LHV).

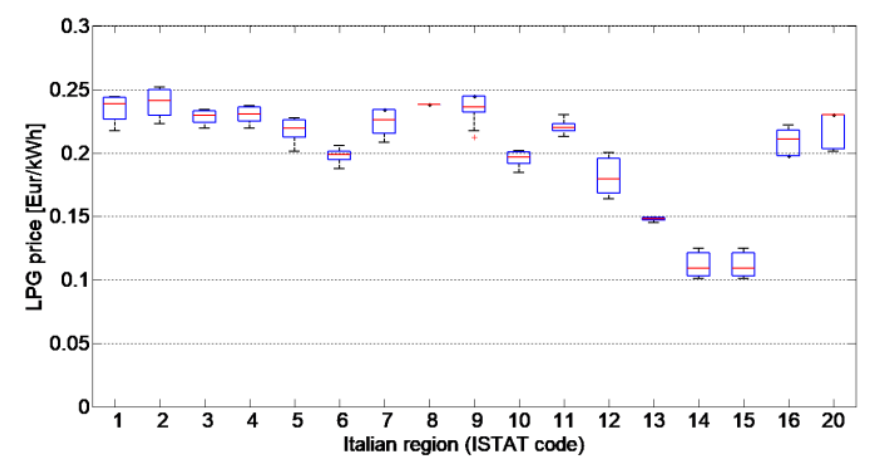

Source: ENEA elaborations of data obtained from the database of list prices of oil products of selected provincial Chambers of commerce in Italy

Figure 2. Regional list prices of LPG delivered in tanks up to $15 \mathrm{~kg}$ in the residential market

As regards LPG, there is not a National Authority that regulates the prices, similarly to natural gas; instead, the provincial Chambers of commerce collect the list prices communicated by local distributors twice per month. In the context of the present study, the price of LPG was obtained for each Region from a province that was selected based on the population (very few data were found on the local sales of LPG, therefore population was used as the reference criteria). Two delivery methods were considered: LPG sold in tanks up to $15 \mathrm{~kg}$, which is a common solution for cooking, and LPG sold in bulk for tanks up to $5,000 \mathrm{~L}$, which is a more common option for space heating and DHW. The average domestic list prices for tanks up to $15 \mathrm{~kg}$ are depicted in Figure 2, which shows both the variability (boxplots) and the medians (red line inside the boxes) during years $2012-2013$. The average price for LPG sold in bulk was about $18 \%$ higher, mainly because 
tax (i.e. VAT) was higher (even if there were remarkable differences from province to province). According to personal communications with operators in the market of the LPG distribution, discounts of $10 \%$ and $25 \%$ to the list prices were applied to LPG in tanks up to $15 \mathrm{~kg}$ and to LPG sold in bulk, respectively.

As regards the other fuels, the following average prices with tax were used: 14.5 cent $€ / \mathrm{kWh}$ for diesel oil (elaboration of data taken from MiSE), 4.46 cent $€ / \mathrm{kWh}$ for wood logs and 6.38 cent $€ / \mathrm{kWh}$ for wood pellets (from a market survey)

\section{RESULTS AND DISCUSSION}

\subsection{Main outcomes from the survey}

ISTAT survey on energy consumption of households represented the basic source of input data for the model. The statistical analysis revealed that in 2013 Italian families spent over 42 billion Euros for the energy bill, with an average expense per family of 1,635 Euros. Figure 3 summarises the average actual expenditures of Italian families for energyrelated products, calculated as the ratio between the gross costs in the last 12 months and the number of families that purchased the fuel. Diesel oil registered the highest average gross expense per family, while LPG the lowest. On a territorial level, the expenses were $30 \%$ higher in Northern than in Southern Italy (with a difference of about 400 Euros per family). The average cost increased with the number of occupants and the age, even if there was no direct proportionality with these quantities.

The main fuel for space heating and DHW was natural gas, used by more than $70 \%$ of the families. As summarised in Table 2 (that refers only to the main heating systems), biomass, LPG and electricity were more common with portable or fixed appliances, while diesel oil was still used in more than $11 \%$ of centralised space heating systems. The independent heating system was the most common type, both for space heating (in $66 \%$ of the families) and for DHW (74\% of the families).

Local heating appliances were more common in Southern Italy (31\% for space heating and $29 \%$ for DHW), while centralised heating systems were used above all in Northwestern Italy ( $31 \%$ for space heating and $10 \%$ for DHW), mainly because of the colder winter season in these regions. The majority of families $(65 \%)$ used the same heat generator both for space heating and for DHW. Secondary DHW systems were sporadic; hence, they were not considered in the model.

Biomass was used by a significant part of the population; more than $20 \%$ families used wood logs, with an average annual consumption of 3.2 ton, while pellets were limited to $4.1 \%$. As expected, the wood consumption was higher in the mountain municipalities (above $40 \%$ of the families).

The space heating systems were turned on every day during the heating season in $87 \%$ of the families, but with significant local differences (98\% in Bolzano, $62 \%$ in Sicily).

As regards cooking appliances, in the statistical dataset ovens and hobs were available in $93 \%$ and $99 \%$ of the households, respectively. According to the fuel, $14 \%$ of the ovens used natural gas, $81 \%$ electrical energy, $4 \%$ LPG and 1

$\%$ biomass (wood log or pellets), while $73 \%$ of the hobs used natural gas, $4 \%$ electricity, 22\% LPG and less than $1 \%$ biomass. More details of the results of the ISTAT survey can be found in [28].

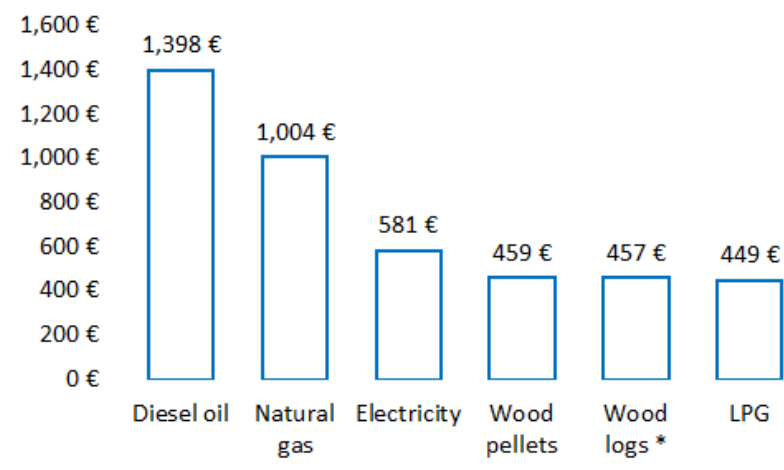

Source: Istat Survey on energy consumption of households - 2013

* Note. Data for wood logs refer only to the purchased quota; they do not consider the self-produced quantities.

Figure 3. Average actual expenditures in a year of Italian families for energy products

Table 2. Families (percent) by type of fuel and typology of the main heating system, both for space heating and DHW

\begin{tabular}{|c|c|c|c|c|c|}
\hline & \multicolumn{5}{|c|}{ Space heating } \\
\hline & Centralised & Independent & $\begin{array}{c}\text { "Fixed" } \\
\text { appliances }\end{array}$ & $\begin{array}{l}\text { "Portable" } \\
\text { apppliances }\end{array}$ & Total \\
\hline Natural gas & 83.8 & 86.5 & 6.1 & & 70.9 \\
\hline Electricity & 1.4 & 0.4 & 17.7 & 54.2 & 5.1 \\
\hline Biomass & 0.7 & 4.8 & 73.9 & & 14.5 \\
\hline LPG & 2.5 & 5.3 & 2.3 & $45.8 *$ & 5.8 \\
\hline \multirow[t]{3}{*}{ Diesel oil } & 11.6 & 3.0 & & & 3.7 \\
\hline & \multicolumn{5}{|c|}{ Domestic hot water } \\
\hline & Centralised & Independent & Local & boilers & Total \\
\hline Natural gas & 80.8 & 83.9 & & 26.0 & 71.9 \\
\hline Electricity & 2.3 & 0.9 & & 66.8 & 14.4 \\
\hline Biomass & 1.5 & 2.7 & & 1.6 & 2.4 \\
\hline LPG & 4.4 & 8.6 & & 5.0 & 7.6 \\
\hline Diesel oil & 10.7 & 2.9 & & 0.6 & 2.9 \\
\hline Solar Thermal & 0.1 & 1.0 & & & 0.7 \\
\hline
\end{tabular}

\subsection{Model calibration and results}

As detailed in the Methodology, the calibration of the model was aimed at finding the proper average values of the relevant parameters for DHW and cooking. In fact, the models should be able to estimate the energy consumption of households between two subsequent surveys. In order to achieve this objective, the survey data was used to calibrate the following parameters, which strongly affected the users' consumption and were directly related to their daily needs: the average daily hot water demand for DHW, and the average load per cycle of the hobs for cooking.

The percent deviation between the model and the survey was calculated on a record-by-record basis according to the following formula (subscript $m$ and $s$ refer to the model and to the survey, respectively):

$\Delta E C=\frac{E C_{s}-E C_{m}}{E C_{m}} \times 100$

The calibration was divided into three steps. In the first step, only cooking was considered: the calculated energy consumption was compared with the records of the ISTAT survey in which each fuel was used only for cooking, in order 
to avoid approximations related to space heating and DHW, which would involve uncertainties comparable to the target variable (i.e. the energy consumption for cooking). From a statistical point of view, the robustness of the estimates depended on the sample size associated with the specific enduses. The sample size associated to each fuel led to select LPG as the reference fuel for this analysis, because the number of records where LPG was used exclusively for cooking (considering also secondary equipment for space heating) was the most representative. In fact, as summarised in Table 3, LPG was used exclusively for cooking in 2,165 records (that is $49 \%$ of the records using LPG for cooking), much larger than natural gas (657 over 14,450 that is $4.6 \%)$. As regards biomass, the number of records that could be used was too small for reliable results, i.e. only six records corresponding to $3.6 \%$ of the 168 records were biomass was used for cooking. Therefore, the average load per cycle of the hobs - expressed in terms of $\mathrm{kg}$ of water heated up according to the standard test procedure - was determined for LPG by minimising the median deviation between the selected data from the survey and the model. The result was $1.86 \mathrm{~kg}$ of water per capita, and it was applied to the other fuels as well, because it depended mainly on the user behavior and much less significantly to the fuel. Figure summarises the relative deviation of the model from the statistical "actual" data related to the annual energy consumption for cooking.

The boxplots represent the interquartile ranges while the (red) intermediate lines represent the median for each distribution. Moreover, the notches below and above the median display the variability of the median between samples. The width of a notch is computed so that box plots whose notches do not overlap have different medians at the 5\% significance level. The significance level is based on a normal distribution assumption, but comparisons of medians are reasonably robust for other distributions. Whiskers extend from each end of the box to the adjacent values in the data; by default, the most extreme values are within 1.5 times the interquartile range from the ends of the box. Outliers (displayed with a red + sign) are data with values beyond the ends of the whiskers [25]

As shown by the width of the box in Figure 4, the model for cooking consumption fitted quite well with records associated with LPG. Instead, higher deviations were found for natural gas, since both the median and the width of the box were sensibly higher: the model underestimated to half the natural gas consumption obtained from the survey. This result may be largely due to the lower robustness of the data sample related to this fuel (the comparison was made on $4.6 \%$ of the records, which used natural gas only for cooking), which may increase the probability to consider record with incomplete information. In particular, some records were characterised by energy consumptions unusually high for cooking only, i.e. above $5,000 \mathrm{kWh} / \mathrm{y}$ per capita. As regards biomass, the median deviation of $0 \%$ (i.e. model in line with the survey data) was a good result; nevertheless, the minimal data sample (only six records) did not allow guaranteeing adequate reliability for this fuel. It is important to emphasise that no standard test procedure and benchmark were found for domestic biomass appliances, consequently the assumptions done could be very approximate. Moreover, biomass appliances are used also for space heating, hence the relative contribution is difficult to extrapolate and quantify.

In the next step, the daily hot water demand per capita was tuned on the records where each fuel was used only for DHW production. As reported in Table, LPG had the highest data sample, with 172 records, while biomass had the lowest representativeness, with only 13 records. Therefore, LPG was used also for the calibration of the DHW model, which resulted in an average daily hot water demand of $60 \mathrm{~L}$ per capita, which was between the demand prescribed by UNI 9182 for social housing (40 - $50 \mathrm{~L})$ and for middle class housing $(70-80 \mathrm{~L})$. The deviations obtained for each fuel are depicted in Figure 5, which shows that similar considerations outlined for cooking were also valid for DHW. In this case, the median deviation for natural gas and biomass increased to $63 \%$ and $86 \%$, respectively. The high relative deviation between the survey and the model for these fuels was largely due to the lower robustness of the estimates determined by the small data sample associated to DHW uses.

Table 3. Available number of records where each fuel was associated exclusively to a specific end-use

\begin{tabular}{cccc}
\hline Fuel* & Cooking & DHW & $\begin{array}{c}\text { Cooking } \\
\text { + DHW }\end{array}$ \\
\hline Natural gas & $657(4.6 \%)$ & $43(0.3 \%)$ & 1151 \\
& 2165 & $17.6 \%)$ \\
LPG & $(49.0 \%)$ & $(9.5 \%)$ & $\begin{array}{c}(58.3 \%) \\
\text { Diesel oil }\end{array}$ \\
& n/a & 93 & 93 \\
& $(10.1 \%)$ & $(10.1 \%)$ \\
\hline
\end{tabular}

* Note. The small data sample associated with biomass for dedicated end-uses was not adequate for a reliable calibration as regards this fuel.

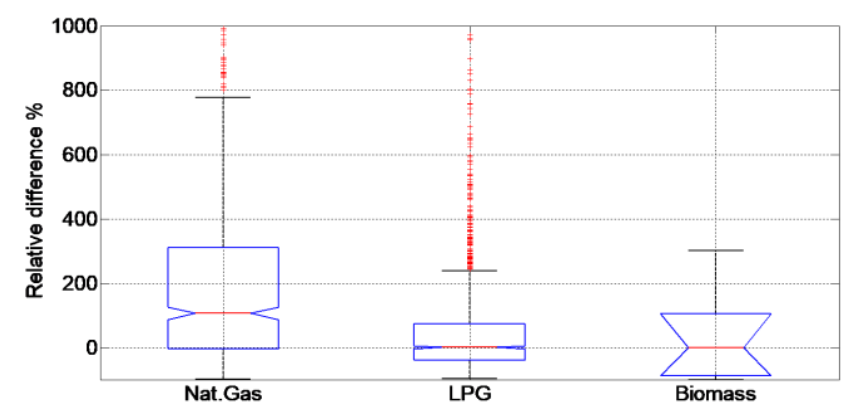

Figure 4. Relative difference survey vs. model for cooking

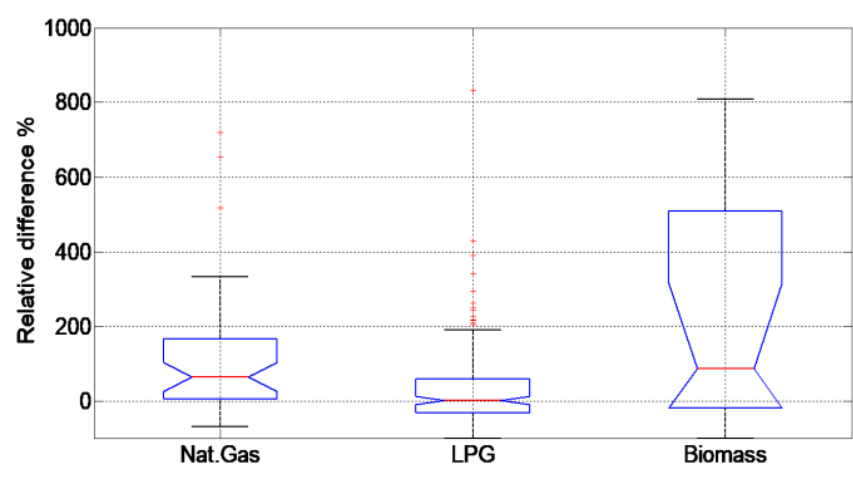

Figure 5. Relative difference survey vs. model for DHW

The effectiveness of the tuned values of the selected parameters was checked in the last step of the calibration, by considering all the records in which a fuel was used either for DHW or for cooking, or for both uses. A shown in Figure 6, the selected values confirmed good results for LPG (median deviation was limited to $-7.8 \%$, i.e. the model slightly overestimated the energy consumption), while they improved 
the median deviation with natural gas and biomass, i.e. $47 \%$ and $31 \%$ respectively. Unfortunately, the calibration was unsuccessful for diesel oil, because the selected daily hot water demand underestimated, on an average, by a factor of four the selected data sample (diesel is not used for cooking). The reasons of such large discrepancies must be found in the small data sample (only 93 records), but also in some inconsistencies of the statistical data for diesel oil, e.g. costs of the bill approximate or provided in a (large) range of values. Moreover, some data suggested that this fuel was indicated in the dataset only for DHW but actually it could be used also for space heating.

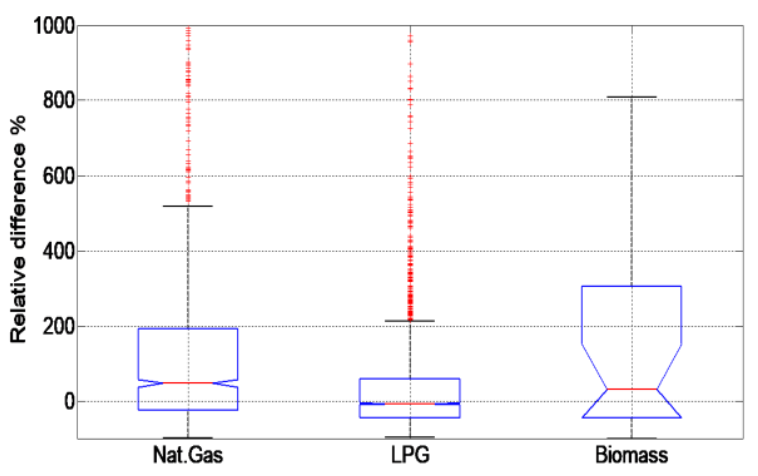

Figure 6. Relative difference survey vs. model for records using a fuel exclusively for DHW or cooking

Table 4. Average (median) annual consumption $(\mathrm{kWh} / \mathrm{y})$ for DHW and cooking calculated by the model

\begin{tabular}{ccccr}
\hline Fuel & \multicolumn{2}{c}{ Family } & \multicolumn{2}{c}{ Per capita } \\
& Cooking & DHW & Cooking & DHW \\
\hline Nat. gas & 1086 & 2399 & 543 & 1120 \\
LPG & 1049 & 2515 & 483 & 936 \\
Diesel & n/a & 3054 & n/a & 1258 \\
Biomass & 4267 & 4638 & 1585 & 1633 \\
Average & 1229 & 2399 & 578 & 1080 \\
\hline
\end{tabular}

The average annual consumptions for DHW and cooking calculated by the model for each family and per capita level are summarised in Table. The results related to DHW were obtained with the global seasonal efficiencies calculated on the basis of reference values taken from [16-17], leading to the values summarised in Figure 7. As described in the Methodology, generation efficiencies depended on the age, the type and the fuel of the system. Similarly, distribution losses depended on the age and the type of the system. In the last version of the model, the absence of recirculation in centralised and independent DHW systems was associated with an increase of $20 \%$ of hot water supply, while on the other side the presence of recirculation was associated with a $20 \%$ increase in the distribution loss. Moreover, the presence of thermal energy storages was accounted by a thermal loss of $10 \%$. If solar collectors were available for DHW production, the model assumed an average annual solar fraction of $50 \%$ (or up to $75 \%$ according to the total collector area) of the net energy demand for hot water.

Regardless of the fuel, the average (median) annual energy consumption for cooking calculated by the model was:

- 1,229 kWh (i.e. $3.37 \mathrm{kWh} /$ day) for the average family unit;

- $578 \mathrm{kWh}$ (i.e. $1.58 \mathrm{kWh} /$ day) per person;

- 1,086 kWh for the hobs;

Therefore, the energy demand calculated for the hobs was almost one order of magnitude higher than ovens, thus explaining why the average mass load per cycle of the hobs was selected for the calibration of the model for cooking uses. $156 \mathrm{kWh}$ for the ovens.

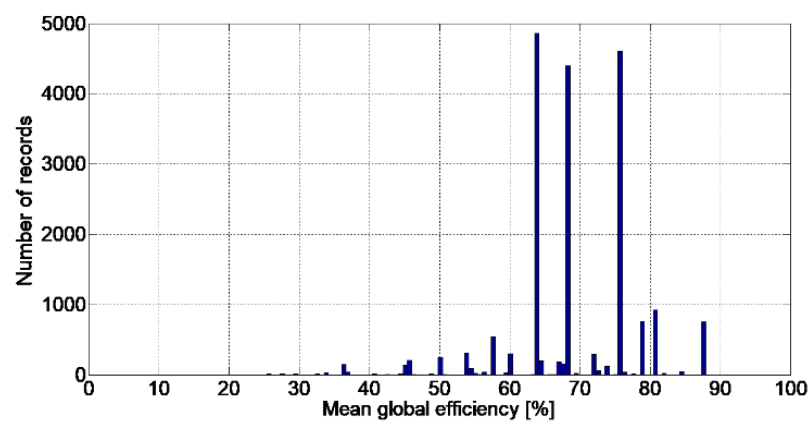

Figure 7. Average calculated DHW seasonal global efficiency

These results were compared with the benchmarks found in the literature. According to edition 2008 of part 2 of the Italian technical specification UNI/TS 11300, the daily energy consumption for domestic cooking would be:

- $4 \mathrm{kWh}$, for dwellings up to $50 \mathrm{~m}^{2}$ of floor area;

- $5 \mathrm{kWh}$, between $50 \mathrm{~m}^{2}$ and $120 \mathrm{~m}^{2}$;

- $6 \mathrm{kWh}$, above $120 \mathrm{~m}^{2}$ of floor area.

Moreover, in the district of Turin in North-Western Italy, the annual energy consumption for cooking uses was estimated around $350 \mathrm{kWh}$ per capita by the authors of [29]. As regards the annual energy consumption of single appliances, some benchmarks were found in [30]: electrical hobs (with a total burner heating rate of $3 \mathrm{~kW}$ and an average daily use of 45 minutes) consume around 1,100 kWh/year, while electrical ovens consume from $65 \mathrm{kWh}$ to $100 \mathrm{kWh}$ per year. It is worth to highlight that the energy demand is greatly influenced by the user behaviour, which affects the usage frequency and length of the cooking cycles.

The average annual energy consumption per floor area for space heating and for each dwelling-type class on a national basis is summarised from Table 5 to Table 8 . Regardless of the fuel, the energy consumption per area increased with the age and decreased for the dwellings with smaller external surfaces (apartments and middle floor apartment in particular). In addition to the thermo-physical and geometrical properties, the space heating demand was significantly influenced by the geographical distribution, the climatic zones and by the number of hours of operation of the heating system.

Table 5. Average annual consumption per floor area $\left(\mathrm{kWh} / \mathrm{m}^{2} / \mathrm{y}\right)$ for space heating with natural gas

\begin{tabular}{c|cccc}
\hline $\begin{array}{c}\text { Type of } \\
\text { dwelling }\end{array}$ & Before 1950 & Construction period \\
\hline SFH & 263 & 229 & 1970 -'89 $^{\prime}$ & After 1990 \\
MFH & 246 & 215 & 144 & 145 \\
GFA & 163 & 114 & 91 & 136 \\
MFA & 73 & 58 & 35 & 34 \\
TFA & 136 & 92 & 79 & 80 \\
\hline
\end{tabular}

Regarding the space heating consumption, the comparison between the survey and the results of the model, summarized in Table 9, showed that the model underestimated the energy consumption for natural gas of about $20 \%$ and slightly overestimated the consumption of diesel oil (about 10\%), 
whereas larger differences were found for the other fuels. These values were obtained by comparing the results of the model with the records of the survey were each fuel was used only in the primary space heating system.

Table 6. Average annual consumption per floor area $\left(\mathrm{kWh} / \mathrm{m}^{2} / \mathrm{y}\right)$ for space heating with LPG

\begin{tabular}{c|cccc}
\hline $\begin{array}{c}\text { Type of } \\
\text { dwelling }\end{array}$ & Before 1950 & 1950-'69 & $1970-$ '89 & After 1990 \\
\hline SFH & 247 & 178 & 110 & 118 \\
MFH & 241 & 222 & 101 & 106 \\
GFA & 119 & 67 & 53 & 69 \\
MFA & 47 & 33 & 23 & 19 \\
TFA & 82 & 49 & 39 & 45 \\
\hline
\end{tabular}

Table 7. Average annual consumption per floor area $\left(\mathrm{kWh} / \mathrm{m}^{2} / \mathrm{y}\right)$ for space heating with diesel oil

\begin{tabular}{c|cccc}
\hline $\begin{array}{c}\text { Type of } \\
\text { dwelling }\end{array}$ & Before 1950 & Construction period \\
\hline SFH & 328 & 274 & 1970 -'89 $^{\prime}$ & After 1990 \\
MFH & 307 & 277 & 184 & 198 \\
GFA & 212 & 127 & 122 & 199 \\
MFA & 108 & 70 & 40 & 453 \\
TFA & 158 & 132 & 99 & 175 \\
\hline
\end{tabular}

Table 8. Average annual consumption per floor area $\left(\mathrm{kWh} / \mathrm{m}^{2} / \mathrm{y}\right)$ for space heating with biomass

\begin{tabular}{c|cccc}
\hline $\begin{array}{c}\text { Type of } \\
\text { dwelling }\end{array}$ & Before 1950 & Construction period \\
\hline SFH & 331 & 255 & $1970-^{-'} 89$ & After 1990 \\
MFH & 296 & 237 & 157 & 166 \\
GFA & 252 & 161 & 112 & 143 \\
MFA & 125 & 80 & 49 & 54 \\
TFA & 189 & 137 & 112 & 126 \\
\hline
\end{tabular}

Table 9. Average (median) space heating consumption $(\mathrm{kWh} / \mathrm{y})$, and cumulative difference of the survey vs. Model

\begin{tabular}{cccl}
\hline Fuel & Survey & Model & Difference \\
\hline Nat. gas & 9552 & 7934 & $20.4 \%$ \\
LPG & 1197 & 3710 & $-67.7 \%$ \\
Diesel oil & 7586 & 8456 & $-10.3 \%$ \\
Biomass & 11100 & 17933 & $-38.1 \%$ \\
\hline
\end{tabular}

Further analysis is required in order to evaluate the reasons of such differences, which can be mainly attributed to the following factors:

-The space heating model allocated all the consumption to the fuel used in the main/primary heating system, since the data collected in the survey for secondary heating systems were not as detailed as required to directly assess their energy consumption;

-The uncertainty associated with the estimation of the energy consumption from the expenditures obtained from the survey;

- The approximations made in the estimation of the thermophysical characteristics of the dwelling-type classes (i.e. opaque envelope type, transparent envelope type, thermal capacitance) were obtained on a national basis, whereas there can be significant differences at regional and local levels;

-The assumptions made for the HDD; in particular, each climatic zone was represented by a reference location.
On an aggregate level at national level, the calculated energy consumption for space heating, DHW and cooking slightly overestimated the energy consumption for natural gas (of about 6\%), which was the most representative fuel in the residential sector since it was used by approximately $70 \%$ of the Italian families according to the survey. The overestimations for the other fuels varied between approx. 22\% (LPG) and 35\% (biomass), as reported in Table 10. Contrary to the comparisons related to the single end-uses described before, the aggregate results were compared on the whole dataset of the survey, regardless of the end-use and without distinctions on the type of system and between primary or secondary heating systems.

Figure 8 shows the quota of each end-use calculated by the models on a national level; biomass and diesel oil were mostly used for space heating, with quota exceeding $91 \%$ and $87 \%$, respectively, while LPG registered larger quotas for DHW $(19 \%)$ and cooking $(22 \%)$. As regards natural gas, space heating covered $74 \%$ of the total consumption, followed by DHW (16\%) and cooking (10\%).

Table 10. Median of the aggregate energy consumption $(\mathrm{kWh} / \mathrm{y})$ without distinction of the end-use, and difference survey vs. Model

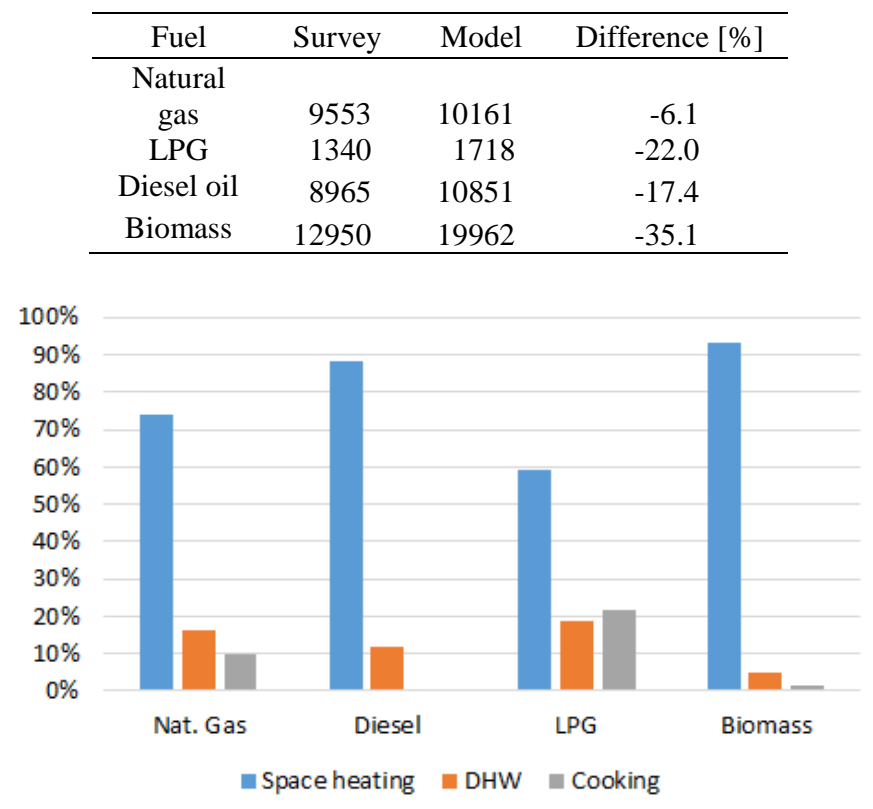

Figure 8. Calculated allocation of the energy consumption according to the fuel and the end-use

\section{CONCLUSIONS}

The numerical tool described in the present paper was aimed at determining the energy consumption for space heating, domestic hot water and cooking in households, based on a statistical dataset of 20,000 records collected in a survey on the energy consumption of Italian families carried out by the National Institute of Statistics. The energy consumption for space heating was based on the definition of dwelling-type classes and calculated with the equivalent resistancecapacitance model of the European standard EN ISO 13790. The energy consumption for DHW and cooking was modeled using a Standard-based approach, and results were compared on a record-by-record basis on the ISTAT survey. 
The current version of the numerical code was refined with new features, starting from an updated automated algorithm for the congruity check of the statistical dataset. Moreover, the presence of hot water recirculation and of storage tanks were included in the model for DHW and new reference prices for natural gas and LPG were based on regional data instead of national averages. The selection of the records for the calibration of the relevant parameters in order to estimate the energy consumption for DHW and cooking was refined by accounting for the presence of secondary space heating equipment.

From a statistical point of view, the robustness of the model calibration depended on the sample size associated with the specific end-uses. For this reason, LPG was selected as the reference fuel, because the number of records where LPG was used exclusively for cooking or DHW was the most representative. The deviation between the model and the survey provided acceptable results for LPG and, to a minor degree, for natural gas and biomass, mainly because of the small data sample associated to the specific end-uses.

As regards space heating, the model showed promising results as far as natural gas and diesel oil were concerned. The main reasons of the deviations depended on the fact that the space heating model allocated all the consumption to the fuel used in the primary heating system, and also to the approximations underlying the dwelling-type classes, and the assumptions made on the heating degree-days.

The energy consumptions were calculated for each fuel and end-use. As regards the aggregate energy consumption on a national basis, the model slightly overestimated (about 6\%) the natural gas consumption, which was used by approx. $70 \%$ of the Italian families according to the ISTAT survey. The overestimations for the other fuels varied between approx. $22 \%$ for LPG and $35 \%$ for biomass.

Biomass and diesel oil were mostly used for space heating, while LPG registered larger consumption fractions for DHW and cooking. As regards natural gas, space heating covered $74 \%$ of the total consumption, then DHW (16\%) and cooking $(10 \%)$.

The refinement and validation of the model are still in progress, since they are functional for the assessment of the energy consumption of households in the period between two subsequent surveys. Future works will focus on extending the validation of the model on the electrical equipment, and on addressing to the issues related to the space heating model.

\section{ACKNOWLEDGMENTS}

This research was part of the Electric System Research project, implemented under the 2015-2017 Programme Agreement between the Italian Ministry for the Economic Development and ENEA.

\section{REFERENCES}

[1] Italian Parliament, Law (2016). 232.

[2] Italian inter-ministerial Decree (2016). Aggiornamento della disciplina per l'incentivazione di interventi di piccole dimensioni per l'incremento dell'efficienza energetica e per la produzione di energia termica da fonti rinnovabili. (in Italian).
[3] Agenzia nazionale efficienza energetica. (2017). Rapporto annuale efficienza energetica - Analisi e risultati delle policy di efficienza energetica del nostro Paese, ENEA, Rome, Italy, Report RAEE-2017.

[4] Yan D, O'Brien W, Hong T, Feng X, Gunay HB, Tahmasebi F, Mahdavi A. (2015). Occupant behavior modeling for building performance simulation: Current state and future challenges. Energy and Buildings 107: 264-278. https://doi.org/10.1016/j.enbuild.2015.08.032

[5] Chen S, Yang W, Yoshino H, Levine MD, Newhouse K, Hinge A. (2015). Definition of occupant behavior in residential buildings and its application to behavior analysis in case studies. Energy and Buildings 104: 1-13. https://doi.org/10.1016/j.enbuild.2015.06.075

[6] Delmastro C, Mutani G, Schranz L, Vicentini G. (2015). The role of urban form and socio-economic variables for extimating the building energy savings potential at the urban scale. International Journal of Heat and Technology 33(4): 91-100. https://doi.org/ 10.18280/ijht.330412

[7] Poel B, Van Cruchten G, Balaras CA. (2007). Energy performance assessment of existing dwellings. Energy and Buildings 39: 393-403. https://doi.org/ 10.1016/j.enbuild.2006.08.008

[8] Ballarini I, Corgnati SP, Corrado V. (2014). Use or reference buildings to assess the energy savings potentials of the residential building stock: The experience of TABULA project. Energy Policy 68: 273284. https://doi.org/10.1016/j.enpol.2014.01.027

[9] Caldera M, Corgnati SP, Filippi M. (2008). Energy demand for space heating through a statistical approach: application to residential buildings. Energy and Buildings $\quad 40$ : 1972-1983. https://doi.org/10.1016/j.enbuild.2008.05.005

[10] Spoladore A, Borelli D, Devia F, Mora F, Schenone C. (2016). Model for forecasting residential heat demand based on natural gas consumption and energy performance indicators. Applied Energy 182: 488-499. https://doi.org/10.1016/j.apenergy.2016.08.122

[11] Soldo B. (2012). Forecasting natural gas consumption. Applied Energy 92: 26-37. https://doi.org/10.1016/j.apenergy.2011.11.003

[12] Puglisi G, Zanghirella F, Ungaro P, Cammarata G. (2016). A methodology for the generation of energy consumption profiles in the residential sector. International Journal of Heat and Technology 34(3): 491497. https://doi.org/10.18280/ijht.340320

[13] Capizzi G, Lo Sciuto G, Cammarata G, Cammarata M. (2017). Thermal transients simulations of a building by a dynamic model based on thermal-electrical analogy: Evaluation and implementation issue. Applied Energy 199:

323-334. https://doi.org/10.1016/j.apenergy.2017.05.052

[14] Energy performance of buildings - Calculation of energy use for space heating and cooling (2008). EN ISO 13790.

[15] Impianti di alimentazione e distribuzione d'acqua fredda e calda - Progettazione, installazione e collaudo (2010). UNI Standard 9182, Italy.

[16] Prestazioni energetiche degli edifici - Parte 2: Determinazione del fabbisogno di energia primaria e dei rendimenti per la climatizzazione invernale, per la produzione di acqua calda sanitaria, per la ventilazione e per l'illuminazione in edifici non residenziali (2014). UNI/TS Standard 11300 Part 2, Italy. 
[17] Italian inter-ministerial Decree 26/06/2015. Description of the reference building and test parameters, Chapter 3, Annex 1, Appendix A (in Italian)

[18] Eurostat. (2013). Manual for statistics on energy consumption in households, from http://ec.europa.eu/eurostat/documents/3859598/593582 5/KS-GQ-13-003-EN.PDF/baa96509-3f4b-4c7a-94ddfeb1a31c7291

[19] Commission Delegated Regulation (EU) No 65/2014 of 1 October 2013 supplementing Directive 2010/30/EU of the European Parliament and of the Council with regard to the energy labelling of domestic ovens and range hoods (2014). Official Journal of the European Union.

[20] Commission Regulation (EU) No 66/2014 of 14 January 2014 implementing Directive 2009/125/EC of the European Parliament and of the Council with regard to ecodesign requirements for domestic ovens, hobs and range hoods (2014). Official Journal of the European Union.

[21] Household electric cooking appliances - Part 2: Hobs Methods for measuring performance (2013). CEI EN Standard 20350 Part No. 2.

[22] Presutto M, Villani MG, Scarano D, Fumagalli S. (2010). Il mercato degli elettrodomestici e la sua evoluzione temporale, ENEA, Italy, Report RdS/2010/255, from http://www.enea.it/it/Ricerca_sviluppo/documenti/ricerc a-di-sistema-elettrico/tecnologie-riduzione-consumi/5rapporto-indagine-mercato.pdf

[23] Cooperativa Sociale Eliante Onlus. Forni Elettrici a Incasso, from www.eurotopten.it, accessed on July 2017.

[24] Hager TJ, Morawicki R. (2013). Energy consumption during cooking in the residential sector of developed nations: a review. Food Policy 40: 54-63. https://doi.org/10.1016/j.foodpol.2013.02.003

[25] DOE (2012). Energy Conservation Program: Test Procedures for Conventional Cooking Products, DOE, USA, from https://energy.gov/sites/prod/files/2015/06/f23/conventi onal_ovens_tp_finalrule.pdf

[26] AEEG. Condizioni economiche di fornitura del gas naturale per il servizio di tutela, from http://www.autorita.energia.it/it/dati/condec_gas.htm.

[27] The Mathworks. MATLAB ${ }^{\circledR}$ Statistics Toolbox ${ }^{\text {TM }}$ User Guide.

[28] ISTAT, I consumi energetici delle famiglie, from http://www.istat.it/it/archivio/142173, accessed on Sep. 2017 (in Italian)

[29] Fracastoro GV, Serraino M. (2009). Valutazione delle prestazioni energetiche degli edifici alla scala provinciale, Politecnico di Torino, Torino, Italy, from http://www.provincia.torino.gov.it/ambiente/filestorage/download/energia/pdf/relazione_polito_eff_fina le.pdf

[30] Conti P, et al. (2011). Definizione di una metodologia per l'audit energetico negli edifici ad uso residenziale e terziario, ENEA, Italy, Report RdS/2011/143, from http://www.enea.it/it/Ricerca_sviluppo/documenti/ricerc a-di-sistema-elettrico/risparmio-energia-settorecivile/rds-143.pdf

\section{NOMENCLATURE}

$E C$

ED

EEI

$H D D$

$n$

$Q$

$S$

SEC

$T$

V

Greek symbols

$\varepsilon$

Subscripts

$\begin{array}{ll}\text { apt } & \text { apartment } \\ \mathrm{m} & \text { model } \\ \text { occ } & \text { occupants/persons } \\ \mathrm{S} & \text { survey } \\ \text { W } & \text { water }\end{array}$

Abbreviations and acronyms

DTC

GFA

MFA

MFH

SFH

TFA

number of persons

floor surface, $\mathrm{m}^{2}$

temperature, $\mathrm{K}$

volume, $\mathrm{m}^{3}$

efficiency thermal capacity, $\mathrm{kJ} / \mathrm{kg}^{-1} / \mathrm{K}^{-1}$

energy consumption, $\mathrm{kWh}$

energy demand, $\mathrm{kWh}$

energy efficiency index, \%

heating degree days

thermal energy, $\mathrm{kWh}$

standard energy consumption, $\mathrm{kWh}$ or $\mathrm{MJ}$

dwelling-type class

ground floor apartment

middle floor apartment

multi-family house

single-family house

top floor apartment 